Dariusz Kulesza*

\section{Przygotowanie do dialogu z islamem}

DOI: http://dx.doi.org/10.12775/LC.2020.018

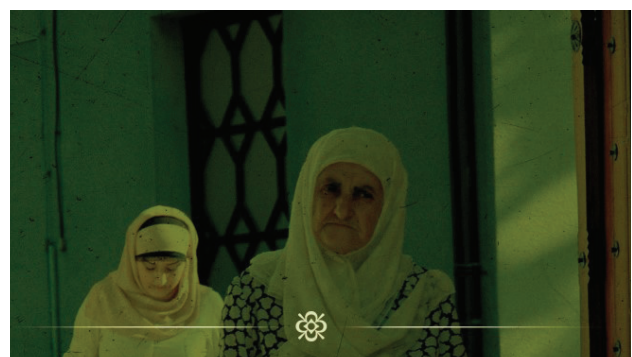

MUSLIMEAST

IN SLAVIC LITERATURES AND CULTURES
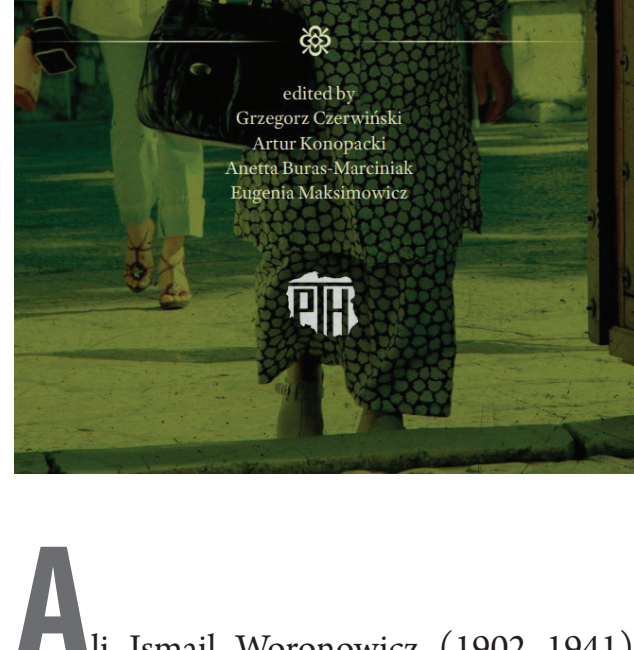

li Ismail Woronowicz (1902-1941) i Mustafa Aleksandrowicz (1911-2000) to polscy Tatarzy, którzy w latach 30 . XX wieku studiowali na Uniwersytecie Al-Azhar w Kairze. Pierwszy z nich spędził na jednej $\mathrm{z}$ najstarszych muzułmańskich uczelni 3 lata (sierpień 1933-wrzesień 1936),

* Profesor nauk humanistycznych, na Wydziale Filologicznym Uniwersytetu w Białymstoku.

E-mail: d.kulesza@uwb.edu.pl | ORCID: 00000002-1250-6696. drugi przebywał tam nieco krócej (styczeń 1934-wrzesień 1936). Obaj podczas pobytu $\mathrm{w}$ Egipcie zgłębiali nie tylko normy prawa muzułmańskiego, śpiew psalmowy, recytację Koranu, życie Proroka, kaligrafię czy higienę, ale także pisali artykuły opowiadające o istocie islamu rozpisanej na jego historię, geografię i aktualną politykę, kwestie religijne, społeczne i kulturę. Publicystyka Woronowicza i Aleksandrowicza była publikowana w latach 1934-1938 na łamach dwóch pism: „Życia Tatarskiego” i „Przeglądu Islamskiego".

W 2014 roku Grzegorz Czerwiński przygotował do druku antologię międzywojennego reportażu polskich Tatarów, gdzie obok tekstów Leona Kryczyńskiego i Edigego Szynkiewicza znalazły się reportaże Alego Woronowicza i Mustafy Aleksandrowicza. Rzecz cała nosi tytuł Podróże do serca islamu. Publicystyce obu studentów Uniwersytetu Al-Azhar poświęcona jest książka „Ali Woronowicz i Mustafa Aleksandrowicz w Egipcie. Materiały źródłowe i publicystyka z lat 1934-1938”. Publikacja ta, spełniająca warunki edycji naukowej teksów źródłowych, została zredagowana i opracowana przez badaczy z Wydziału Filologicznego Uniwersytetu w Białymstoku: Grzegorza Czerwińskiego i Eugenię Maksimowicz. Wstęp napisał Grzegorz Czerwiński. Liczącą niewiele ponad 200 stronic całość w roku 2019 opublikowało białostockie Wydawnictwo Stowarzyszenia Absolwentów Wydziału Prawa UwB - Temida 2. Obok artykułów polskich Tatarów znalazły się w niej dokumenty z lat 1935-1936, zachowane w Archiwum Akt Nowych w Warszawie. Dotyczą one pobytu Woronowicza i Aleksandrowicza w Egipcie. Zawierają korespondencję między Wydziałem Wschodnim Departamentu Polityczno-Ekonomicznego Ministerstwa Spraw Zagranicznych II RP, Instytutem Wschodnim oraz Poselstwem Rzeczypospolitej Polskiej w Kairze. 
Szczególne znaczenie w tym zbiorze posiada przygotowany przez Woronowicza i Muhammada Sajjida al-Hamawiego skrót broszury „Islam w Polsce”.

Punktem wyjścia oceny książki, przygotowanej przez Grzegorza Czerwińskiego i Eugenię Maksimowicz, powinno być stwierdzenie, że jest ona aktualna i potrzebna. Potrzebna jest publicystyka Alego Woronowicza i Mustafy Aleksandrowicza. Potrzebują jej, jak sądzę, polscy Tatarzy i polscy muzułmanie. Potrzebują jej badacze islamu w Polsce i na świecie tak samo, jak badacze historii i literatury II RP. W nie najmniejszym stopniu książka ta wydaje się użyteczna z punktu widzenia wszystkich zainteresowanych tym, co dzisiaj, na progu trzeciej dekady XXI wieku, nie tyle dzieje się w świecie, ile o losach tego świata: naszego i coraz bardziej globalnego, w dużej mierze decyduje. Takie znaczenie: dokumentalne, historyczne i współczesne ma książka „Ali Woronowicz i Mustafa Aleksandrowicz w Egipcie”.

Lata 30., Egipt, Uniwersytet Al-Azhar, dwóch stypendystów z Polski, polskich Tatarów studiuje swoją tożsamość. Woronowicz i Aleksandrowicz mieli możność uczyć się islamu nie jako jednej z monoteistycznych religii księgi, ale jako jedynej religii uniwersalnej, fundamentu muzułmańskiej cywilizacji, dzięki której „człowiek potrafi wznieść się ponad zło przez czynienie dobra będącego najwyższym nakazem islamu drogą zjednania miłości bliźniego" (2019: 32). Ta panislamska perspektywa jest bezcenna, by z punktu widzenia Zachodu, do którego chcemy należeć, łatwiej było zrozumieć Wschód, na który ludzie Zachodu zwykli patrzeć z góry, jakbyśmy nie mogli pozbyć się perspektywy (post)kolonialnej, chociaż zwykliśmy powtarzać, że przecież my, Polacy, z kolonializmem XIX i XX wieku nie mieliśmy nic wspólnego.

Islamska tożsamość zapisana w książce przygotowanej przez Grzegorza Czer- wińskiego i Eugenię Maksimowicz jest czytelna dla współczesnego odbiorcy, zarówno profesjonalisty, jak i laika m.in. dzięki temu, że źródłem wiedzy o niej są osoby z jednej strony należące do islamu, znającego go, identyfikujące się $\mathrm{z}$ nim, a jednocześnie mocno osadzone w realiach Zachodu, przekraczającego ograniczenia międzywojennej Polski. Woronowicz i Aleksandrowicz: muzułmanie, publicyści i studenci, patrzą na islam i piszą o nim z perspektywy jednej z najważniejszych muzułmańskich uczelni tamtego czasu, z Egiptu, którego znaczenie po upadku imperium osmańskiego znacznie wzrosło. Trudno zatem o bardziej odpowiednie osoby, miejsce i czas, by poznawać źródła tego islamu, z którym dzisiaj nie potrafi się porozumieć ponowoczesny, współczesny świat.

Teksty Woronowicza i Aleksandrowicza mają charakter publicystyczny. Dzięki temu nie brakuje im odwagi nie tylko kompetentnego, ale także syntetycznego i komunikatywnego konfrontowania się $\mathrm{z}$ tematami zasadniczymi, definiującymi islam w kontekście jego istoty, postrzeganej $\mathrm{w}$ kategoriach religijnych, czyli najważniejszych oraz społecznych, antropologicznych i kulturowych, niebagatelizowanych. Islam w publicystyce obu autorów to jego historia, przywołująca m.in. doświadczenia tureckie, a właściwie osmańskie, wspólczesność, uwikłana w politykę zagraniczną prowadzoną na muzułmańskim Wschodzie przez mocarstwa europejskiego Zachodu oraz w nacjonalizm Arabów, Turków, Persów czy Hindusów. To także widziana z perspektywy lat 30 . XX wieku przyszłość islamu, determinowana przez ruchy religijno-polityczne $\mathrm{w}$ rodzaju wahhabityzmu, przez kwestię palestyńską, ale także przez kulturę, zarówno zapisaną w eposie „Szahname" Ferdousiego, Homera Iranu, jak i zapisywaną we współczesnej literaturze Egipcjan 
Generalizując: Czerwiński i Maksimowicz zdecydowali się na publikacje tych artykułów bohaterów swojej książki, które dotyczą przede wszystkim kwestii politycznych i społecznych. Wybór ten wydaje się zasadny. Wolałbym jednak, by wstęp Grzegorza Czerwińskiego - autora ważnej monografii „«Jam z rodu nomadów». Literatura polsko-tatarska po 1918 roku” (Białystok 2017), cenionego edytora literatury polsko-tatarskiej i współredaktora pokonferencyjnych monografii - dostarczył więcej wiadomości na temat tego, co do prezentowanego wyboru nie weszło. Pragnienie to w dużej mierze, pośrednio, rekompensują informacje na temat charakteru i zawartości pism decydujących o tożsamości publicystyki tatarskiej dwudziestolecia międzywojennego: „Życia Tatarskiego” i „Przeglądu Islamskiego", ale artykuły Woronowicza i Aleksandrowicza są do tego stopnia zajmujące, że potrzebę poznawczą i zwyczajną ciekawość ich czytelnika trudno zaspokoić najobfitszym, najobszerniejszym nawet edytorskim opracowaniem. Dwa czytelnicze niezaspokojenia chciałbym zrelacjonować.

Wstęp ogranicza się do przeglądu tematów podejmowanych w „Życiu Tatarskim” i „Przeglądzie Islamskim”. Przyjmuję to rozwiązanie, ale pozwolę sobie zgłosić do jego realizacji dwie uwagi. Uwaga pierwsza: Czerwiński w swoim tematycznym przeglądzie wskazuje m.in. kwestię kobiecą, co wydaje się zrozumiałe ze względu na wagę tego tematu wtedy (lata 30. XX wieku), a zwłaszcza dzisiaj. $\mathrm{Z}$ drugiej jednak strony można odnieść wrażenie, że ani Woronowicz, ani Aleksandrowicz sprawie tej nie poświęcają zbyt wiele czasu. A przecież sprawy mają się inaczej. Wystarczy zajrzeć do przywoływanej już antologii „Podróże do serca islamu”, by znaleźć w niej, komentowane przez badacza, artykuły Woronowicza zatytułowane „Kobieta egipska” czy „Islam a kobieta”. Z jednej strony naturalne jest unikanie autoplagiatu czy mieszania gatunków omawianych tekstów, ale chcialbym, żeby Grzegorz Czerwiński w większym stopniu odwoływał się do tego, co o Woronowiczu oraz Aleksandrowiczu pisał w „Podróżach...” i w „Literaturze polsko-tatarskiej po 1918 roku". Póki co, Czerwiński komentując kwestię kobiecą we wstępie do książki „Ali Woronowicz i Mustafa Aleksandrowicz w Egipcie”, przywołuje głównie artykuły innych tatarskich publicystów. Uwaga druga dotyczy Ormian. Mniej obciąża edytorów, ale wydaje się poważniejsza, bo przekracza granice zagadnień autorsko-edytorsko-intertekstualnych,. Dzisiejszy czytelnik nie potrafi zapomnieć o tym, co stało się w 1915 roku w Turcji z Ormianami. Nacja ta jest wspomniana $\mathrm{w}$ jednym $\mathrm{z}$ umieszczonych w książce artykułów, ale poza kontekstem określanym dzisiaj przez międzynarodową opinię publiczną jako ludobójstwo. Problem wciąż pozostaje nierozwiązany, ale byłoby lepiej, gdyby pojawił się we wstępie i w przypisach.

Godząc się na bardzo dyskretną obecność w książce obojga badaczy, wywołam jeszcze jedną, osobną, zasadniczą kwestię. Rzecz w tym, że czytając teksty, przede wszystkim Aleksandrowicza, łatwo zauważyć konsekwencję w opisywaniu historii islamu powiązanej z historią świata. Widać to na poziomie powtórzeń, które świadczą głównie o tym, że przyszły polski dyplomata dysponuje i stosuje konsekwentnie w swojej publicystyce taką historiozofię, która dużo mówi nie tylko o jego wykształceniu, ale przede wszystkim o determinowanym przez islam postrzeganiu historii oraz wynikającym stąd społecznym i politycznym profetyzmie. Trudno byłoby we wstępie napisać tylko o tym, przekraczając standard tematycznej prezentacji, ale nie zmienia to faktu, że brakuje mi głosu edytorów, brakuje mi ich intensywniejszej: komentującej i syntetyzującej obecności. Jakby, niebezzasadnie, 
i Grzegorz Czerwiński, i Eugenia Maksimowicz wierzyli w skuteczność bezpośredniego oddziaływania tekstów bohaterów swojej książki, usuwając się w cień, chroniący ich publikację przed komentarzami zbyt publicystycznymi, odwołującymi się ryzykownie do aktualnych, polityczno-gospodarczych napięć. Nie zmienia to faktu, że książka „Ali Woronowicz i Mustafa Aleksandrowicz w Egipcie" stanowi bardzo użyteczny materiał dla wszystkich, którzy chcą i próbują zrozumieć islam nie tylko sprzed II wojny światowej, ale także ten, z którym współcześnie, w globalizującym się świecie mamy do czynienia.

Edytorska wstrzemięźliwość Czerwińskiego i Maksimowicz sprawdza się przy prezentacji dokumentów ze zbiorów Akt Nowych w Warszawie. Ministerstwo Spraw Zagranicznych II RP w swojej korespondencji z Instytutem Wschodnim aż nazbyt czytelnie ujawnia reguły decydujące o jego funkcjonowaniu, karykaturalnie niemal podporządkowane dość wąsko rozumianemu interesowi państwa. Na tym tle muzulmański punkt widzenia obu polsko-tatarskich publicystów wypada niewinnie, wręcz naturalnie. I nie ma się czemu dziwić. Z jednej strony urząd i gorliwie pragmatyczni urzędnicy, a z drugiej dwaj (wy)kształceni muzułmanie świadomi tożsamości muzułmańskiego Wschodu niemal tak dobrze jak Zachodu reprezentowanego przez międzywojenną Polskę. Nie widzę zatem powodu, by nalegać na opatrzenie cytowanych dokumentów przypisami, jeśli jednak zastosować i w tym wypadku regułę nie dość zaspokojonego czytelniczego głodu, przypisów nigdy dosyć.

A skoro o technikaliach mowa, brakuje mi w związku z nimi jasnego i konsekwentnego postępowania dotyczącego np. powracających w artykule, opatrzonych przypisami nazwisk. Najczęściej Czerwiński i Maksimowicz przypisy po prostu powtarzają, co ułatwia lekturę skuteczniej niż stosowanie odwołań do wcześniej podanych informacji, ale nie wydaje mi się, by była to reguła praktykowana we wszystkich przypadkach. Poruszam kwestie techniczne nie po to, by polemizować $\mathrm{z}$ wydawcą czy edytorami. Przypisy w publikacjach tego typu to coś więcej niż jedno $\mathrm{z}$ podstawowych zadań wydawnictwa funkcjonującego na rynku książek naukowych. Bez przypisów Ali Woronowicz i Mustafa Aleksandrowicz stają się niekomunikatywni. A to, co każdy $\mathrm{z}$ nich ma do powiedzenia o islamie jest zbyt ważne, by na niekomunikatywność ich publicystyki można było sobie pozwolić. W tym miejscu kłaniam się z uznaniem Pani Eugenii oraz Panu Grzegorzowi i wracam do technikaliów, bo przecież w związku z nimi chodzi nie tylko o przypisy dotyczące religii, historii, geografii, kultury czy personaliów, ale także o kwestie językowe. Edytorzy w zasadach wydania piszą o modernizowaniu ortografii, interpunkcji i fleksji, co nie budzi wątpliwości, ale wydaje mi się, że - podobnie jak przypisy - nie zostało zrealizowane dość konsekwentnie. Wrażenie to może być błędne, ponieważ - inaczej niż Grzegorz Czerwiński i Eugenia Maksimowicz - jestem zwolennikiem ingerencji w język pierwowzoru na szerszą skalę. Uwspółcześniłbym nie tylko ortografię, interpunkcję i fleksję, ale także składnię, przynajmniej w tym zakresie, na jaki wskazuje moja lektura, dostrzegająca drobne potrzeby w tym zakresie.

Pozostaje pytanie zasadnicze, nieredakcyjne: czy teksty muzułmanów, nawet tych polskich, europejskich, zachodnich, mogą być dla postchrześcijańskiego Zachodu komunikatywne? Jaką konsekwencję, edytorsko-językową, zastosować, by Zachód mógł je czytać i rozumieć? Czy jest ona ogóle możliwa? A jeśli jest, to w jaki sposób ją zdefiniować i wcielić? Pisanie o przypisach i języku to początek realizowania naturalnej 
i koniecznej, coraz bardziej aktualnej potrzeby skutecznego komunikowania się $\mathrm{z}$ wyznawcami islamu, $\mathrm{z}$ ich religią, historią, kulturą i cywilizacją. Przygotowana do druku przez Grzegorza Czerwińskiego i Eugenię Maksimowicz książka „Ali Woronowicz i Mustafa Aleksandrowicz w Egipcie. Materiały źródłowe i publicystyka z lat 19341938” dialog z islamem umożliwia, ponieważ dostarcza na jego temat wiadomości podstawowych i ważnych, opracowanych dyskretnie i użytecznie, podanych przez dwóch polskich Tatarów: autorów kompetentnych i przystępnych. Nie bez znaczenia jest fakt, że wiadomości te pochodzą sprzed niemal stu lat. I nie są formułowane $\mathrm{z}$ utrudniającą lekturę intencją, którą nawet postchrześcijanin nazwałby ewangelizacyjną. Dzięki temu Woronowicz i Aleksandrowicz raczej uczą, niż angażują w aktualne: polityczne, gospodarcze czy kulturowe napięcia. I w ten sposób stwarzają szansę rozmowy, a w każdym razie dobrze do niej przygotowują.
Bibliografia

Czerwiński, Grzegorz [\&] Artur Konopacki (red.) 2015. Estetyczne aspekty literatury polskich, białoruskich i litewskich Tatarów (od XVI do XX w.). Białystok: Alter Studio.

Czerwiński, Grzegorz 2016. „Dwóch tatarskich emigrantów, dwa przeciwstawne modele biografii: Edige Szynkiewicz (Kırımal) i Mustafa Aleksandrowicz". W: Violetta Wejs-Milewska [\&] Ewa Rogalewska (red.). Paryż, Londyn, Monachium, Nowy Jork. Powrześniowa emigracja niepodlegtościowa na mapie kultury nie tylko polskiej. T. 2. Białystok: Oddział Instytutu Pamięci Narodowej w Białymstoku, Wydawnictwo Uniwersytetu w Białymstoku.

— 2017. "Jam z rodu nomadów”. Literatura polsko-tatarska po 1918 roku. Białystok: Alter Studio.

__ et al. (red.) 2019. Muslim East in Slavic Literatures and Cultures. Białystok: Polskie Towarzystwo Historyczne.

Podróże do serca islamu. Antologia międzywojennego reportażu polskich Tatarów 2014. Wstęp, wybór, oprac. Grzegorz Czerwiński. Białystok: Alter Studio 